\title{
A Case Control Study on Risk Factors Associated with Low Birth Weight Babies in Eastern Nepal
}

\author{
Ravi Kumar Bhaskar, ${ }^{1}$ Krishna Kumar Deo, ${ }^{2}$ \\ Uttam Neupane, ${ }^{3}$ Subhadra Chaudhary Bhaskar, ${ }^{4}$ Birendra Kumar Yadav, ${ }^{5}$ \\ Hanoon P. Pokharel, ${ }^{6}$ and Paras Kumar Pokharel ${ }^{5}$ \\ ${ }^{1}$ Department of Community Medicine and Public Health, National Medical College, Birgunj, Parsa 44300, Nepal \\ ${ }^{2}$ HelpAge International, Kathmandu 44600, Nepal \\ ${ }^{3}$ Research Triangle Institute International, Kathmandu 44600, Nepal \\ ${ }^{4}$ Narayani Sub-Regional Hospital, Birgunj, Parsa 44300, Nepal \\ ${ }^{5}$ School of Public Health and Community Medicine, B.P. Koirala Institute of Health Sciences, Dharan, Sunsari 56700, Nepal \\ ${ }^{6}$ Department of Obstetrics and Gynaecology, B.P. Koirala Institute of Health Sciences, Dharan, Sunsari 56700, Nepal
}

Correspondence should be addressed to Ravi Kumar Bhaskar; hi.vaskar@yahoo.com

Received 11 August 2015; Revised 28 October 2015; Accepted 23 November 2015

Academic Editor: Patrick Brophy

Copyright (C) 2015 Ravi Kumar Bhaskar et al. This is an open access article distributed under the Creative Commons Attribution License, which permits unrestricted use, distribution, and reproduction in any medium, provided the original work is properly cited.

Background. This study was done to assess the maternal and sociodemographic factors associated with low birth weight (LBW) babies. Methods. An unmatched case control study was done involving 159 cases (mothers having LBW singleton babies) and 159 controls (mothers having normal birth weight singleton babies). Results. More than $50 \%$ of LBW babies were from the mothers with height $\leq 145 \mathrm{~cm}$ while only $9.43 \%$ of NBW babies were from the mothers with that height. Finally, after multivariate logistic regression analysis, maternal height, time of first antenatal care (ANC) visit, number of ANC visits, iron supplementation, calcium supplementation, maternal education, any illness during pregnancy, and hypertension were found as the significant predictors of LBW. However, maternal blood group AB, normal maternal Body Mass Index (BMI), mother's age of 30 or more years, and starting ANC visit earlier were found to be protective for LBW. Conclusion. Study findings suggest that selectively targeted interventions such as delay age at first pregnancy, improving maternal education and nutrition, and iron and calcium supplementation can prevent LBW in Nepal.

\section{Introduction}

Low birth weight (LBW) has been defined by WHO as weight at birth of less than $2.5 \mathrm{~kg}[1]$. By international agreement, LBW has been defined as a birth weight of less than 2500 grams, with the measurement being taken preferably within the first hour of life, before significant postnatal weight loss has occurred [2]. It contributes substantially to neonatal, infant, and childhood mortality and morbidity [3].

Across the world, neonatal mortality is 20 times more likely for LBW babies compared to NBW babies $(>2.5 \mathrm{~kg}$ ) [4]. It is now a well recognized fact that birth weight is not only a critical determinant of child survival, growth, and development, but also a valuable indicator of maternal health, nutrition, and quality of life [5].

The incidence of LBW is estimated to be $16 \%$ worldwide, $19 \%$ in the least developed and developing countries, and 7\% in the developed countries. The incidence of LBW is $31 \%$ in South Asia followed by East and North Africa (15\%), SubSaharan Africa (14\%), and East Asia and Pacific (7\%). Asia accounts for $75 \%$ of worldwide LBW followed by Africa (20\%) and Latin America (5\%). In Nepal, the LBW prevalence is relatively high, ranging from 14 to $32 \%$, as documented from various hospital and community based studies [6]. In a study done in Nepal, the LBW rate was found to be $27 \%$ out of which LBW babies at term constitute $70 \%$ and LBW babies before term (preterm) constitute 30\% [7]. 
Only $36 \%$ of children born in Nepal were weighed at birth. Among them, $12 \%$ are of low birth weight. The percentage of children with LBW varies from $15 \%$ in mountains to $13 \%$ in Pahad (hills) and $12 \%$ in Terai (plain land areas) [8].

This study was done to assess the maternal and sociodemographic factors associated with LBW babies, an important indicator of maternal and newborn health in Nepal.

\section{Materials and Methods}

A hospital based unmatched case control study was carried out at two hospitals: B.P. Koirala Institute of Health Sciences (BPKIHS), Dharan, and Koshi Zonal Hospital (KZH), Biratnagar, in east Nepal. Both hospitals are referral hospitals in the region. BPKIHS is 700 bedded teaching hospital while $\mathrm{KZH}$ is 300 bedded hospital. The high uptake of services at these hospitals is probably owing to their low cost. After admission, the majority of births take place within 2 days. The hospital stay is usually at least 1 day after delivery unless the mother or infant experiences problems or the mode of delivery was surgical.

The study data were collected between September 2011 and February 2012 by using interview technique. Eligible mothers were interviewed face to face within 24 hours after delivery. Abstraction of ANC cards and medical records of mothers were also made and anthropometric measurements were taken after interview.

2.1. Cases and Controls. Mothers delivering live born singleton term baby with birth weight less than 2500 gm were taken as cases, while mothers delivering live born singleton term baby with birth weight 2500 gm or more were taken as controls. The mothers delivering babies of more than 4 kilograms or babies with congenital anomalies or twins or preterm babies were excluded from the study.

2.2. Sample Size. Sample size was estimated using software Epi Info 7.0 version and cross-checked using software nMaster 2.0 version. The sample size estimation was done taking $80 \%$ power, $5 \%$ alpha error, and 2 as anticipated odds ratio. One hundred and fifty-nine cases and the same number of controls were included in the study. Questionnaire was translated into local language and pretested before data collection. Mothers were interviewed by researchers only.

2.3. Ethical Issues. Ethical clearance was obtained from the Institutional Ethical Review Board of BPKIHS. Before starting the interview, verbal individual consent for participation was taken after the study's aim, methods, benefits, and the potential discomfort were adequately explained. Subjects were informed that they were free to abstain or to withdraw from participation at any time. Questions were asked in a way that did not hurt their dignity. The respondents were assured that the answers they give would remain private, anonymous, and confidential.

2.4. Variables. The questionnaire contained the variables on maternal factors (age, weight, height, BMI, parity, ANC check-up, iron (60 mg daily) and calcium (500 mg) supplementation, and interpregnancy interval), sociodemographic factors (religion, ethnicity, occupation, socioeconomic status, educational status of parents, type of family, geographical area, and sex of baby), and diseases during pregnancy (anaemia, night blindness, hypertension, heart diseases, tuberculosis, and eclampsia).

2.5. Statistical Analyses. The filled questionnaires were checked and rechecked for their completeness at the end of the day during data collection. They were coded before the data entry. Data were entered into the MS Excel 2007 version and were analyzed using PASW Statistical software 18.0. Crude and adjusted odds ratios were used to investigate the factors affecting incidence of LBW, by bivariate and multivariate logistic regression, respectively. Bivariate associations between independent variables and low birth weight were analyzed using simple logistic regression, and crude odds ratios and confidence intervals were calculated. Chisquare analysis was used to test possible bivariate associations between independent variables and low birth weight.

Based on the bivariate analysis and a priori information, a multivariate logistic regression model was constructed to examine the relationship between variables and low birth weight, while also considering possible covariate effects. Entry of the exposure variable was forced, followed by stepwise entry of potentially relevant covariates. The HosmerLemeshow test was used to identify and exclude variables that caused poor fit in the model. Independent associations between variables were characterized by adjusted odds ratios and $95 \%$ confidence intervals.

\section{Results}

A total sample of 318 mothers comprising 159 cases and 159 controls were included in the study. Out of 318 subjects, 70.75 percent were from rural area while 29.25 percent were from urban area. More than seventy percent of both the case $(70.44 \%)$ and the control $(71.07 \%)$ groups were from rural area. Majority of the subjects were Hindu (94.02\%). The rest were Muslims (5.03\%) and Christians (0.95\%). Majority of the cases (92.45\%) and controls (95.60) were Hindus. Although they were very few in number, all Hill occupational castes (ethnic groups from hilly area of the country who economically depend upon their traditional occupation) were cases. Muslims were three times more in percentage in case group $(7.55 \%)$ than control $(2.51 \%)$ group while Hill natives were three times more in the control (23.27\%) group than in the case $(7.55 \%)$ group.

Only $24.85 \%$ of total respondents belonged to nuclear family, while the rest belonged to joint (64.46\%) and extended family $(10.69 \%)$. Only $10.03 \%$ of the total controls were illiterate, while $24.53 \%$ of the cases were illiterate.

More than three-fourths of the mothers were housewives while the rest worked outside home. Only 3.14\% of the mothers were involved in business while $7.55 \%$ of them were laborers.

Majority $(46.86 \%)$ of the respondent mothers were of 20-24 years. Teenage mothers constituted $19.18 \%$ of total 
TABLE 1: Comparison of basic variables of mothers between cases and controls.

\begin{tabular}{|c|c|c|c|c|c|}
\hline \multirow{2}{*}{ Characteristics } & \multicolumn{2}{|c|}{ Case group } & \multicolumn{2}{|c|}{ Control group } & \multirow{2}{*}{$p$ value } \\
\hline & Mean & Std. deviation & Mean & Std. deviation & \\
\hline Birth weight (gm) & 2126.73 & 340.13 & 3083.65 & 332.26 & $<0.001^{*}$ \\
\hline Maternal age (years) & 24.07 & 5.09 & 23.38 & 5.01 & 0.23 \\
\hline Family size (number) & 5.58 & 2.51 & 5.45 & 2.39 & 0.63 \\
\hline Monthly income (Rs.) & 12627.17 & 8486.16 & 16332.70 & 13786.85 & $0.003^{@}$ \\
\hline Maternal Weight $(\mathrm{kg})$ & 47.04 & 9.30 & 52.11 & 8.58 & $<0.001^{*}$ \\
\hline Total ANC visits (number) & 3.36 & 1.47 & 4.46 & 1.44 & $<0.001^{*}$ \\
\hline Iron tablet (number) & 98.30 & 47.40 & 129.81 & 48.11 & $<0.001^{*}$ \\
\hline Calcium tablet (number) & 40.94 & 54.12 & 72.64 & 72.81 & $<0.001^{@}$ \\
\hline Hb level (gm/dL) & 11.33 & 1.09 & 11.33 & 1.22 & $0.02^{*}$ \\
\hline Maternal height $(\mathrm{cm})$ & 146.73 & 7.88 & 152.77 & 6.04 & $<0.001^{*}$ \\
\hline Per-capita income (\$) & 1.10 & 0.72 & 1.39 & 1.09 & $0.004^{@}$ \\
\hline
\end{tabular}

${ }^{*}$ Significant $t$-test at $p<0.05,{ }^{\circledR}$ Mann-Whitney $U$ test significant at $p<0.05$.

mothers. More than one-fifth (22.01\%) of the cases were born by teenage mothers, while teenage mothers gave birth to $16.36 \%$ of the controls.

Nearly two-thirds $(63.52 \%)$ of the respondents were below poverty level. Based on modified Kuppuswamy's socioeconomic scale, $44.34 \%$ of total mothers were from the upper lower class while $4.41 \%$ of them were also from lower class. All the mothers from the lower class gave birth to cases.

There was no significant difference in the maternal age between cases and controls. However, the mothers of LBW infants had significantly lower weight than the controls $(p<$ 0.05 ). Table 1 compares the basic variables between case and control groups.

Table 2 explains about the maternal risk factors associated with low birth weight babies. Maternal age, maternal weight, maternal height, and interpregnancy interval were found to be associated with low birth weight (Table 2).

The chances of delivering LBW babies were found to be increased as the mothers started the first ANC visit lately. The association between LBW neonates and the time of the first ANC visit was found to be significantly associated $(p<0.05)$. The mothers who had their first ANC in the third trimester of pregnancy were threefold ( $\mathrm{OR}=3.34,95 \% \mathrm{CI}: 1.14-9.78)$ more likely to give birth to LBW neonates than the mothers who had their first ANC in the first trimester. The chance of having LBW babies was also significantly higher in the mothers who had their first ANC in second trimester $(\mathrm{OR}=1.65,95 \% \mathrm{CI}$ : $1.03-2.63)$.

LBW was found to be significantly associated with the total number of ANC visits $(p<0.001)$. The mothers who had 1 to 2 ANC visits were 16 -fold (OR $=16.74,95 \%$ CI: 6.71-41.95) more prone to have LBW neonates than the mothers who had more than 4 ANC visits in total. The chance of delivering LBW neonates by the mothers who had total ANC visits of 3-4 times was also higher ( $\mathrm{OR}=3.03,95 \% \mathrm{CI}$ : 1.77-5.21).

Iron supplementation was found to be significantly associated with LBW $(p<0.001)$. The mothers who were supplemented with iron for 90 or fewer days were nearly threefold more prone to have LBW babies than the mothers having iron supplementation for more than 90 days.
More than half of the cases (51.57\%) had not taken calcium supplement, while less than one-third of the controls (30.19\%) had not taken the calcium supplement. In control group, the proportion of having calcium supplement for 90 days or more was found more than in the case group. It was more than double the proportion in the controls (40.25\%) compared to the cases (18.24\%). The mothers having no calcium supplement were more likely to have LBW babies than mothers having it for 90 days or more (OR $=3.77,95 \%$ CI: 2.14-6.63). The mothers having iron supplement for 90 or fewer days were also more prone to deliver LBW babies (OR $=3.21,95 \%$ CI: 1.72-5.99).

The association between maternal blood group and LBW babies was also found to be significantly associated $(p<$ 0.05). Maternal blood group $A B$ has some protective effect against delivering low birth weight babies ( $\mathrm{OR}=0.33,95 \%$ CI: 0.13-0.80).

Maternal residence $(p=0.902)$, religion $(p=0.236)$, paternal education $(p=0.213)$, paternal occupation $(p=$ 0.251 ), socioeconomic status based on modified Kuppuswamy scale $(p=0.48)$, and per-capita income $(p=0.162)$ were found to be insignificant. But caste $(p<0.001)$, type of family ( $p=0.013)$, maternal education $(p=0.001)$, maternal occupation ( $p=0.037)$, and type of house $(p=0.009)$ were found to be significantly associated with LBW. The odds ratio was found significant for Muslims (OR $=4.69$, 95\% CI: 1.28 17.10) and major Hill castes (OR $=2.37, \mathrm{CI}: 1.08-5.19)$. Illiterate mothers were more at risk to have LBW babies than mothers who were educated up to SLC or more $(\mathrm{OR}=3.04,95 \% \mathrm{CI}$ : 1.54-5.98). Laborer mothers were three times more common to deliver LBW babies than housewives $(\mathrm{OR}=3.22,95 \% \mathrm{CI}$ : 1.24-8.39). Mothers having katcha (house made of bamboo or mud or other local materials) house were twofold more likely to have LBW neonates than mothers having pucca houses (houses made of bricks, rod, and cement) (OR $=2.06,95 \%$ CI: 1.19-3.55).

Any illness during pregnancy was significantly associated with LBW $(p<0.05)$. Mothers having any illness during pregnancy were at more than twofold risk to have LBW babies compared to mothers having no illness $(\mathrm{OR}=2.49,95 \% \mathrm{CI}$ : 
TABLE 2: Maternal risk factors associated with low birth weight babies.

\begin{tabular}{|c|c|c|c|c|c|c|}
\hline \multirow{2}{*}{ Characteristics } & \multicolumn{2}{|c|}{ Case } & \multicolumn{2}{|c|}{ Controls } & \multirow{2}{*}{ OR (95\% CI) } & \multirow{2}{*}{$p$ value } \\
\hline & $N=159$ & Percentage & $N=159$ & Percentage & & \\
\hline \multicolumn{7}{|l|}{ Maternal age (years) } \\
\hline$<20$ & 35 & 22.01 & 26 & 16.36 & $1.52(0.86-2.71)$ & \multirow{3}{*}{$>0.05$} \\
\hline $20-29$ & 98 & 61.63 & 111 & 69.81 & 1 & \\
\hline$\geq 30$ & 26 & 16.36 & 22 & 13.83 & $1.34(0.71-2.51)$ & \\
\hline \multicolumn{7}{|l|}{ Maternal weight } \\
\hline$\leq 45 \mathrm{~kg}$ & 80 & 50.31 & 39 & 24.50 & $4.91(2.64-9.11)$ & \multirow{3}{*}{$<0.001^{*}$} \\
\hline $45-55 \mathrm{~kg}$ & 56 & 35.23 & 65 & 40.9 & $2.06(1.13-3.77)$ & \\
\hline$\geq 55 \mathrm{~kg}$ & 23 & 14.46 & 55 & 34.60 & 1 & \\
\hline \multicolumn{7}{|l|}{ Maternal height } \\
\hline$\leq 1.45$ meters & 85 & 53.50 & 15 & 9.43 & $11.09(5.27-23.33)$ & \multirow{3}{*}{$<0.001^{*}$} \\
\hline $1.46-1.55$ meters & 51 & 32.08 & 99 & 62.27 & $1.01(0.55-1.85)$ & \\
\hline$>1.55$ meters & 23 & 14.46 & 45 & 28.30 & 1 & \\
\hline \multicolumn{7}{|l|}{ BMI } \\
\hline$<18.5$ & 26 & 16.35 & 14 & 8.80 & $0.93(0.53-1.63)$ & \multirow[t]{3}{*}{0.12} \\
\hline $18.5-24.99$ & 102 & 64.15 & 113 & 71.07 & $1.92(0.85-4.34)$ & \\
\hline$\geq 25$ & 31 & 19.50 & 32 & 20.13 & 1 & \\
\hline \multicolumn{7}{|l|}{ Parity } \\
\hline 1 & 93 & 58.49 & 98 & 61.63 & $0.97(0.60-1.56)$ & \multirow{3}{*}{0.41} \\
\hline 2 & 52 & 32.71 & 53 & 33.33 & 1 & \\
\hline 3 or more & 14 & 8.80 & 8 & 5.03 & $1.78(0.69-4.61)$ & \\
\hline \multicolumn{7}{|c|}{ Interpregnancy interval } \\
\hline$<24$ months & 23 & 29.87 & 14 & 18.18 & $2.65(1.16-6.06)$ & \multirow{3}{*}{$0.03^{*}$} \\
\hline $24-48$ months & 26 & 33.76 & 42 & 54.55 & 1 & \\
\hline$>48$ months & 28 & 36.36 & 21 & 27.27 & $2.15(1.02-4.55)$ & \\
\hline Total & 77 & & 77 & & & \\
\hline \multicolumn{7}{|c|}{ Socioeconomic status } \\
\hline Upper lower ${ }^{@}$ & 78 & 44.65 & 70 & 44.03 & $1.50(0.78-2.92)$ & \multirow[t]{3}{*}{0.48} \\
\hline Lower middle & 61 & 38.36 & 62 & 38.99 & $1.33(0.67-2.62)$ & \\
\hline Upper middle & 20 & 12.58 & 27 & 16.98 & 1 & \\
\hline
\end{tabular}

${ }^{*}$ Significant $(p<0.05) ;{ }^{\circledR}$ lower class also included; OR in bold denotes being significant.

1.46-4.25). Mothers having fever during pregnancy, night blindness, and pain in abdomen during pregnancy were not significantly associated with LBW babies. But hypertension was found to be significantly associated with low birth weight babies. Mothers having hypertension during pregnancy were four times more likely to deliver LBW neonates than mothers having no hypertension ( $\mathrm{OR}=4.25,95 \% \mathrm{CI}$ : 1.17-15.35). Anaemic mothers were also more likely to deliver LBW babies (OR $=1.65$; 95\% CI: 1.05-2.59).

Exposure variables, maternal weight, height, age, time of first ANC visit, total ANC visits, iron supplementation, calcium supplementation, maternal blood group, maternal education, any illness during pregnancy, hypertension, anaemia, BMI, poverty level (per-capita income), and house type, were included in the multivariate regression analysis. Maternal height, time of first ANC visit, total number of ANC visits, iron supplementation, calcium supplementation, maternal education, any illness during pregnancy, and hypertension are the significant predictors of LBW (Table 3).
Maternal blood group AB, normal maternal BMI, mother's age of 30 years or more, and starting ANC visit earlier were found to be significantly protective for LBW from multivariate regression analysis. Likewise, maternal blood group $\mathrm{AB}$ and normal maternal BMI had also protective effect on LBW after adjustment for other variables (Table 3 ).

The variables maternal weight, iron supplementation, anaemia, and poverty level were found to be significantly associated with LBW during univariate logistic analysis; however, those were found to be insignificant after being adjusted for other variables. It means odds ratios were significant, but adjusted odds ratios were not significant.

\section{Discussion}

In this study, maternal age had no significant association with LBW which is consistent with studies conducted by Mavalankar et al. [9] in India and Fikree and Berenes [10] in Pakistan. But, in contrast, Yadav et al. [11] and Joshi et al. 
TABLE 3: Multivariate regression analysis for possible predictors of LBW.

\begin{tabular}{|c|c|c|c|}
\hline Characteristics & AOR & AOR at $95 \% \mathrm{CI}$ & $p$ value \\
\hline \multicolumn{4}{|l|}{ Maternal weight } \\
\hline$\leq 45 \mathrm{~kg}$ & 1.81 & $0.36-9.15$ & 0.473 \\
\hline $45-55 \mathrm{~kg}$ & 2.14 & $0.63-7.26$ & 0.224 \\
\hline$\geq 55 \mathrm{~kg}$ & Ref. & & \\
\hline \multicolumn{4}{|l|}{ Maternal height } \\
\hline$\leq 1.45$ meters & 20.38 & $4.87-85.22$ & $<0.001^{*}$ \\
\hline $1.46-1.55$ meters & 1.81 & $0.64-5.12$ & 0.262 \\
\hline$>1.55$ meters & Ref. & & \\
\hline \multicolumn{4}{|l|}{ Time of 1st ANC visit } \\
\hline First trimester & 0.03 & $0.002-0.51$ & $0.015^{*}$ \\
\hline Second trimester & 0.99 & $0.44-2.25$ & 0.986 \\
\hline Third trimester & Ref. & & \\
\hline \multicolumn{4}{|l|}{ ANC visit (number) } \\
\hline $1-2$ & 172.79 & $23.57-1266.67$ & $0.001^{*}$ \\
\hline $3-4$ & 5.93 & $2.26-15.59$ & $0.001^{*}$ \\
\hline$>4$ & Ref. & & \\
\hline \multicolumn{4}{|l|}{ Iron supplementation } \\
\hline 1-90 days & 0.58 & $0.23-1.49$ & 0.256 \\
\hline 91-180 days & Ref. & & \\
\hline \multicolumn{4}{|l|}{ Calcium supplementation } \\
\hline No & 1.56 & $0.57-4.29$ & 0.388 \\
\hline 1-90 days & 3.57 & $1.22-10.42$ & $0.02^{*}$ \\
\hline 91-180 days & Ref. & & \\
\hline \multicolumn{4}{|l|}{ Blood group } \\
\hline A & 1.18 & $0.48-2.92$ & 0.716 \\
\hline $\mathrm{AB}$ & 0.17 & $0.04-0.76$ & $0.021^{*}$ \\
\hline B & Ref. & & \\
\hline $\mathrm{O}$ & 1.29 & $0.51-3.33$ & 0.590 \\
\hline \multicolumn{4}{|l|}{ Maternal education } \\
\hline Illiterate & 5.69 & $1.83-17.68$ & $0.003^{*}$ \\
\hline Literate & Ref. & & \\
\hline \multicolumn{4}{|l|}{ Any illness during pregnancy } \\
\hline Yes & 4.24 & $1.90-9.44$ & $<0.001^{*}$ \\
\hline No & Ref. & & \\
\hline \multicolumn{4}{|l|}{ Hypertension } \\
\hline Yes & 19.44 & 3.11-121.52 & $0.002^{*}$ \\
\hline No & Ref. & & \\
\hline \multicolumn{4}{|l|}{ Anaemia } \\
\hline Yes $(\mathrm{Hb}<12 \mathrm{gm} / \mathrm{dL})$ & 1.27 & $0.59-2.71$ & 0.534 \\
\hline $\mathrm{No}(\mathrm{Hb} \geq 12 \mathrm{gm} / \mathrm{dL})$ & Ref. & & \\
\hline \multicolumn{4}{|l|}{ Maternal age } \\
\hline$<20$ & 0.36 & $0.12-1.08$ & 0.069 \\
\hline $20-29$ & Ref. & & \\
\hline$\geq 30$ & 0.15 & $0.04-0.53$ & $0.003^{*}$ \\
\hline \multicolumn{4}{|l|}{ BMI } \\
\hline Thin $\left(<18.5 \mathrm{~kg} / \mathrm{m}^{2}\right)$ & 0.91 & $0.13-6.42$ & 0.928 \\
\hline Normal $\left(18.5-24.99 \mathrm{~kg} / \mathrm{m}^{2}\right)$ & 0.19 & $0.05-0.70$ & $0.013^{*}$ \\
\hline Overweight $\left(\geq 25 \mathrm{~kg} / \mathrm{m}^{2}\right)$ & Ref. & & \\
\hline \multicolumn{4}{|l|}{ Per-capita income } \\
\hline$<\$ 1.25$ per day & 1.17 & $0.54-2.57$ & 0.691 \\
\hline$\geq \$ 1.25$ per day & Ref. & & \\
\hline \multicolumn{4}{|l|}{ House type } \\
\hline Katcha & 2.89 & $1.12-7.47$ & $0.0029^{*}$ \\
\hline Pucca & Ref. & & \\
\hline
\end{tabular}

* Significant $(p<0.05)$; AOR in bold denotes being significant.
[12] found more risk of delivering LBW babies by teenage mothers.

Maternal postpartum weight in this study was significantly associated $(p<0.001)$ with the birth weight of the baby which is consistent with some studies $[9,13]$. Low birth weight babies were found to be nearly 5 times $(\mathrm{OR}=4.91$, 95\% CI: 2.64-9.11) more common in the mothers having 45 kilograms or less weight which is in accordance with the study in Nepal [14].

Reliable information on prepregnancy weight or weight gain during pregnancy could not be obtained due to case control nature of this study, and postpartum weight was used. Mollar et al. have shown in African women with a total pregnancy weight gain of $6 \mathrm{~kg}$ that maternal weight within 24 hours postpartum was equal to weight at 14 weeks of gestation [15]. As mean weight gain during pregnancy in India was only about $6 \mathrm{~kg}$ in a study by Anderson [16], it is felt that postpartum weight closely reflects prepregnancy weight in our population. Therefore, postpartum BMI closely reflects prepregnancy BMI.

The association between maternal height and LBW was significantly associated in this study as found in other studies [17], but it is contrasted with another study [14].

The relationship between a low maternal BMI and LBW has been known for several decades. Some studies $[9,18]$ also had the same findings that low maternal BMI was significantly associated with LBW. But, in contrast, low maternal BMI $\left(<18.5 \mathrm{~kg} / \mathrm{m}^{2}\right)$ was not found to be significantly associated with LBW babies in this study which is in accordance with the study by Ojha and Malla [14].

Interpregnancy interval was found to be significantly associated with LBW babies $(p<0.05)$ in this study which is in agreement with Roy et al. [5] and Mumbare et al. [19] but is in contrast with Yadav et al. [20].

The time of the first ANC visit was found to be significantly associated with LBW in this study and it was in accordance with the studies by Kercher [21] but in contrast with Yadav et al. [20].

Singh et al. [17] support the finding of this study that LBW was found to be significantly associated with the total number of ANC visits.

Intake of iron supplements during pregnancy was found to have a protective effect with respect to LBW in this study which is consistent with Rizvi et al. [3]. Maternal anemia in this study was found to be associated with low birth weight when cutoff was $\mathrm{Hb}<12 \mathrm{gm} / \mathrm{dL}$, which is in accordance with the studies by Rizvi et al. [3]. Hypertension was found to be significantly associated with low birth weight babies in this study. The same was documented by Aghamolaei et al. [22] Aghamolaei et al. [22] also support our study that bleeding during pregnancy was found to be significantly associated with LBW babies.

Maternal education was found to be significantly associated with LBW babies in this study as in some previous studies [23], but it is in contrast with Aghamolaei et al. [22]. This study shows insignificant association between birth weight and religion which was suggested by Yadav et al. [20]. 
Maternal occupation was found to be significantly associated with LBW babies in our study which is in accordance with some studies $[22,23]$ but in divergence with Yadav et al. [20]. Per-capita income was not found to be associated with LBW babies in this study which was supported by Yadav et al. [20] but denied by Joshi et al. [12].

LBW babies were more common in mothers having katcha houses than mothers having pucca houses in our study. Rizvi et al. [3] suggest the same finding, while Yadav et al. [20] deny it. As katcha houses reflect poverty in Nepalese society, our finding was also supported by Khan and Jamal's study [24] where they found poverty as a significant factor for LBW.

There was significant negative association between LBW and maternal blood group $\mathrm{AB}$ in our study which is in accordance with the findings of Fedrick and Adelstein [25].

Exposure variables, maternal weight, height, age, time of first ANC visit, total ANC visits, iron supplementation, calcium supplementation, maternal blood group, maternal education, any illness during pregnancy, hypertension, anaemia, BMI, poverty level (per-capita income), and house type, were included in the multivariate regression analysis.

Out of those exposure variables, maternal height, time of first ANC visit, total number of ANC visits, iron supplementation, calcium supplementation, maternal education, any illness during pregnancy, and hypertension were found to be the significant predictors of LBW.

Maternal blood group $\mathrm{AB}$, normal maternal BMI, mother's age of 30 years or more, and starting ANC visit earlier were some variables which were found to be significant but with protective effect for LBW.

\section{Conclusion}

Study findings suggest that selectively targeted interventions such as delay age at first pregnancy, improving maternal education and nutrition, and iron and calcium supplementation can prevent LBW in Nepal.

It is suggested to conduct more comprehensive studies to assess maternal blood groups and different diseases during pregnancy as associated factors for low birth weight babies.

\section{Conflict of Interests}

The authors declare that there is no conflict of interests regarding the publication of this paper.

\section{Authors' Contribution}

Ravi Kumar Bhaskar was involved in the conception and design of the study, data collection, reviewing of literature, and writing of the drafts. Uttam Neupane and Krishna Kumar Deo were involved in concept refining and literature review. Subhadra Chaudhary Bhaskar was involved in data collection. Birendra Kumar Yadav, Hanoon P. Pokharel, and Paras Kumar Pokharel were involved in concept refining and mentoring.

\section{References}

[1] World Health Organization, International Statistical Classification of Diseases and Related Health Problems, Tenth Revision, World Health Organization, Geneva, Switzerland, 1992.

[2] K. Park, Park's Textbook of Preventive and Social Medicine, Banarsidas Bhanot, Jabalpur, India, 20th edition, 2009.

[3] S. A. Rizvi, J. Hatcher, I. Jehan, and R. Qureshi, "Maternal risk factors associated with low birth weight in Karachi: a case control study," Eastern Mediterranean Health Journal, vol. 13, no. 6, pp. 1343-1352, 2007.

[4] S. Badshah, L. Mason, K. McKelvie, R. Payne, and P. J. G. Lisboa, "Risk factors for low birthweight in the public-hospitals at Peshawar, NWFP-Pakistan," BMC Public Health, vol. 8, article 197, 2008.

[5] S. Roy, D. D. Motghare, A. M. Ferreira, F. S. Vaz, and M. S. Kulkarni, "Maternal determinants of low birth weight at a tertiary care," The Journal of Family Welfare, vol. 55, pp. 79-83, 2009.

[6] WHO, "Multicenter study on LBW and infant mortality in India," Nepal and Srilanka Regional Health Paper 25, SEARO, 1994.

[7] MIRA, Low Birth Weight Prevalence and Associated Factors in Four Regions of Nepal, (A Multi-Hospital based study), UNICEF, 2000.

[8] Ministry of Health and Population (MOHP) Nepal, New ERA, and Macro International Inc., Nepal Demographic and Health Survey 2006, Ministry of Health and Population, New ERA, and Macro International Inc., Kathmandu, Nepal, 2007.

[9] D. V. Mavalankar, R. H. Gray, and C. R. Trivedi, "Risk factors for preterm and term low birthweight in Ahmedabad, India," International Journal of Epidemiology, vol. 21, no. 2, pp. 263-272, 1992.

[10] F. F. Fikree and H. W. Berenes, "Risk factors for term intrauterine growth retardation: a community-based study in Karachi," Bulletin of the World Health Organization, vol. 72, no. 4, pp. 581587, 1994.

[11] S. Yadav, D. Choudhary, R. K. Mandal, A. Sharma, S. S. Chauhan, and P. Agrawal, "Adverse reproductive outcomes associated with teenage pregnancy," McGill Journal of Medicine, vol. 11, no. 2, pp. 141-144, 2008.

[12] H. S. Joshi, S. H. Subba, S. B. Dabral, S. Dwibedi, D. Kumar, and S. Singh, "Risk factors associated with low birth weight in neonates," Indian Journal of Community Medicine, vol. 30, no. 4, pp. 142-143, 2005.

[13] H. M. Ehrenberg, L. Dierker, C. Milluzzi, and B. M. Mercer, "Low maternal weight, failure to thrive in pregnancy, and adverse pregnancy outcomes," American Journal of Obstetrics \& Gynecology, vol. 189, no. 6, pp. 1726-1730, 2003.

[14] N. Ojha and D. S. Malla, "Low birth weight at term: relationship with maternal anthropology," Journal of the Nepal Medical Association, vol. 46, no. 166, pp. 52-56, 2007.

[15] B. Moller, M. Gebre-Medhin, and G. Lindmark, "Maternal weight, weight gain and term in the rural Tanzanian village of Hula," British Journal of Obstetrics and Gynaecology, vol. 96, pp. 158-166, 1989.

[16] M. A. Anderson, Relationship between maternal nutrition and child growth in rural India [Doctoral Thesis], Tufts University, Medford, Mass, USA, 1989.

[17] S. D. Singh, S. Shrestha, and S. B. Marahatta, "Incidence and risk factors of low birth weight babies born in Dhulikhel Hospital," Journal of Institute of Medicine, vol. 32, no. 3, pp. 339-342, 2011. 
[18] S. Bhattacharya, D. M. Campbell, W. A. Liston, and S. Bhattacharya, "Effect of body mass Index on pregnancy outcomes in nulliparous women delivering singleton babies," BMC Public Health, vol. 7, article 168, 2007.

[19] S. S. Mumbare, G. Maindarkar, R. Darade, S. Yengl, M. K. Tolani, and K. Patole, "Maternal risk factors associated with term low birth weight neonates: a matched-pair case control study," Indian Pediatrics, vol. 49, no. 1, pp. 25-28, 2012.

[20] D. K. Yadav, U. Chaudhary, and N. Shrestha, "Risk factors associated with low birth weight," Journal of Nepal Health Research Council, vol. 9, no. 19, pp. 159-164, 2011.

[21] L. Kercher, Maternal Risk Factors Associated with Low Birth Weight in Montana, University of Washington, Seattle, Wash, USA, 2008.

[22] T. Aghamolaei, H. Eftekhar, and S. Zare, "Risk factors associated with Intrauterine Growth Retardation (IUGR) in Bandar Abbas," Journal of Medical Sciences, vol. 7, no. 4, pp. 665-669, 2007.

[23] A. Matin, S. K. Azimul, A. K. M. Matiur, S. Shamianaz, J. H. Shabnam, and T. Islam, "Maternal socioeconomic and nutritional determinants of low birth weight in urban area of Bangladesh," Journal of Dhaka Medical College, vol. 17, no. 2, pp. 83-87, 2008.

[24] N. Khan and M. Jamal, "Maternal risk factors associated with low birth weight," Journal of the College of Physicians and Surgeons-Pakistan, vol. 13, no. 1, pp. 25-28, 2003.

[25] J. Fedrick and P. Adelstein, "Factors associated with low birth weight of infants delivered at term," British Journal of Obstetrics and Gynaecology, vol. 85, no. 1, pp. 1-7, 1978. 


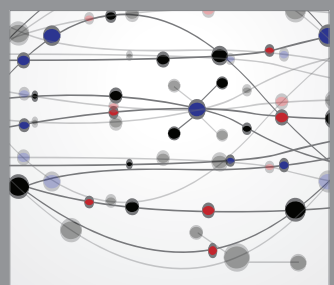

The Scientific World Journal
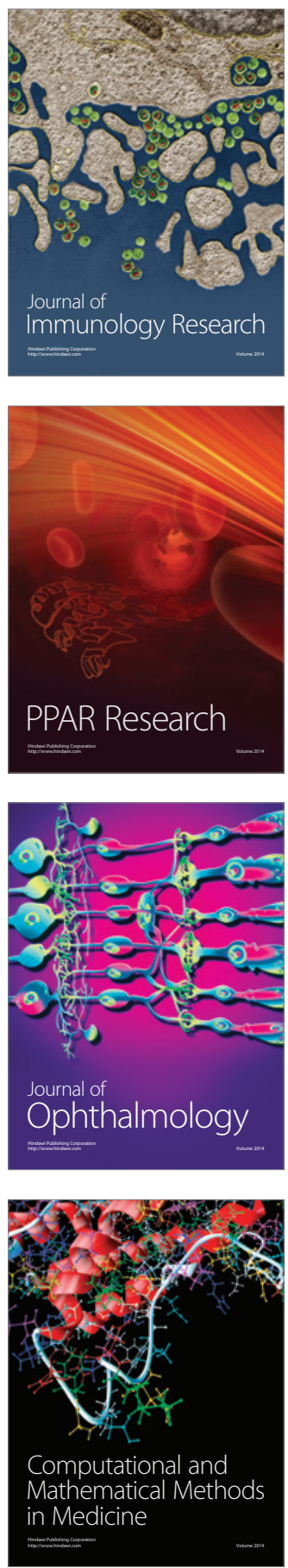

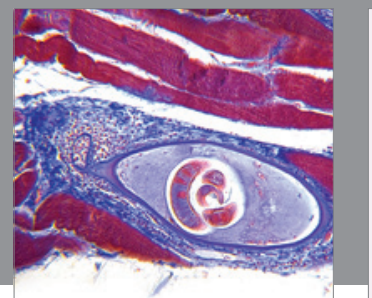

Gastroenterology

Research and Practice
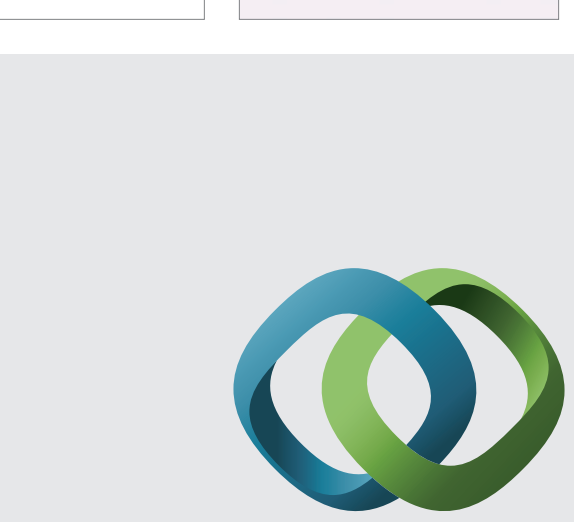

\section{Hindawi}

Submit your manuscripts at

http://www.hindawi.com
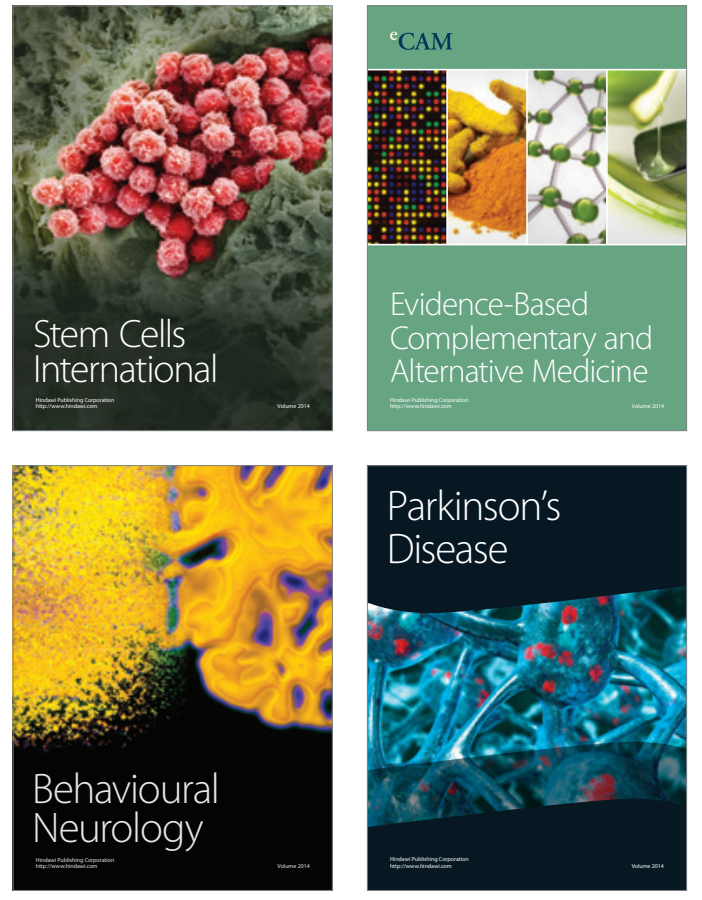
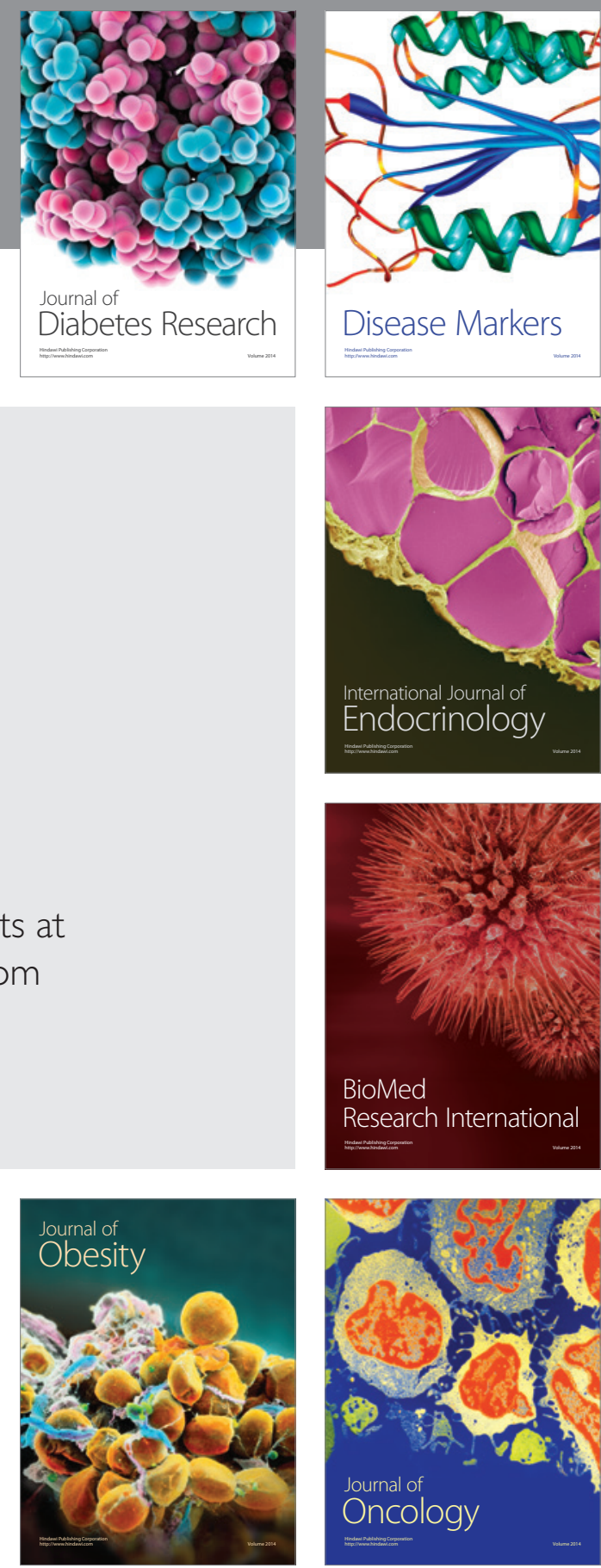

Disease Markers
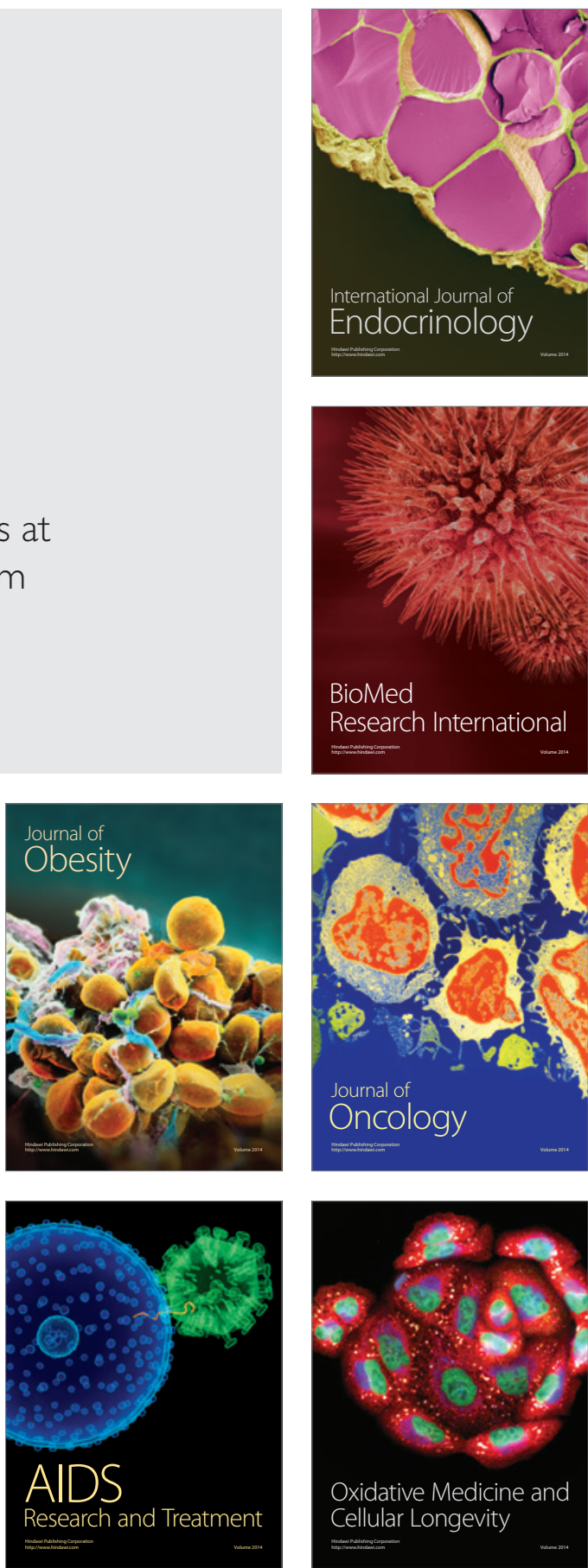